\title{
EXPLANATION AND SOCIAL THEORY
}




\section{Explanation and Social Theory}

John Holmwood

and

Alexander Stewart

St. Martin's Press New York 
(C) John Holmwood and Alexander Stewart 1991

Softcover reprint of the hardcover 1st edition 1991 978-0-333-54545-4

All rights reserved. For information, write:

Scholarly and Reference Division

St. Martin's Press, Inc., 175 Fifth Avenue,

New York, N.Y. 10010

First published in the United States of America in 1991

ISBN 978-1-349-21629-1 ISBN 978-1-349-21627-7 (eBook)

DOI $10.1007 / 978-1-349-21627-7$

Library of Congress Cataloging-in-Publication Data

Holmwood, John, 1950-

Explanation and social theory / John Holmwood and Alexander

Stewart.

p. $\mathrm{cm}$.

Includes bibliographical references and index.

ISBN 978-0-312-06575-1

1. Sociology-Methodology. I. Stewart, Alexander, 1939-

II. Title.

HM24.H566 1991

$301 ' .01-\mathrm{dc} 20$ 


\section{Contents}

List of Figures vi

List of Tables vii

Acknowledgements viii

Preface ix

1 Introduction 1

2 Positivism 11

3 Relativism 26

4 Vertical and Horizontal Fallacies 42

5 Rationality and Action 63

6 Action and Structure $\quad 89$

7 Power and Normative Order 114

8 Structure, Function and Contradiction 135

9 False Consciousness and Ontological Alienation 158

10 Conclusion 177

$\begin{array}{ll}\text { Notes } & 180\end{array}$

Bibliography 225

Index 235 


\section{List of Figures}

4.1 Qualifications of Clerks by Age 49

4.2 First Jobs of Current Clerks 50

4.3 Current Jobs of Starting Clerks 51

4.4 Percentage Promoted by Level of Qualifications 52 


\section{List of Tables}

4.1 Income and Qualifications of Male Occupational Groups 46

4.2 Earnings by First Jobs 53 


\section{Acknowledgements}

A major debt is to those writers whose work we use extensively, if critically, in exposing the problematic substance of modern social theory. In particular, we have personal debts to David Lockwood whose writings were central to our struggles and whose tolerance in argument sharpened our treatments. Our close colleagues in what others have called the 'Cambridge school', Bob Blackburn, Ken Prandy and Janet Siltanen, are due our thanks for their unfailing encouragement and the myriad of ways in which they have contributed to the development of our ideas. Many other colleagues have contributed by reading, discussing and criticising our work. We are especially grateful to Des King who has shown an amazing appetite for successive drafts and an unfailing eye for strengths and weaknesses. Malcolm Waters, too, has been a constant, constructive critic. We should also like to thank Dave Campbell, Bruce Coram, Mike Grimes, Keith Hart, Geoffrey Hawthorn, Frank Jones, Andrew Linklater, Mick Mann, Gunnar Olofsson, Gian Poggi and Jonathan Turner. The support of Else-Marie Carlander and Freida Stewart has been crucial. Over the years, students, especially at the University of Edinburgh, both undergraduate and postgraduate, have contributed more than is usual to our thought and expression. They have been enthusiastic, engaged and critical, in ways which encouraged our efforts and contributed to clarity. In the years it has taken to produce this volume, we have had support from the various institutions in which we have been employed. In thanking them, and our colleagues in general, we should like to acknowledge a special debt to the Department of Applied Economics at the University of Cambridge, which supported the work from its inception, and to the Department of Sociology of the Research School of the Social Sciences, Australian National University, which provided each of the authors with an environment which was both stimulating and supportive at crucial times in the development of the work.

We would like to thank the following publishers for permission to cite material: Basil Blackwell for J. Habermas The Theory of Communicative Action, Harper Collins for A. Giddens' New Rules of Sociological Method and MacMillan for A. Giddens' Central Problems in Social Theory. 


\section{Preface}

This book arose out of deep and extensive dissatisfactions with procedures and explanations in the social sciences. At every point that explanations became problematic there seemed to be a recourse to special pleading that the problems be accepted rather than solved. The motives for this were, superficially, positive and generous. It was argued that behaviours problematic to the social scientist were to be accepted in their meaningfulness to social actors. The very ability to confound social scientists was held to be the expression of human freedom and creativity. As a consequence, the social sciences would always be ex post, interpretive and imprecise. Our unease with this position was not confined to any general desire that the social sciences should be capable of greater precision and generality. More importantly, we found every particular invocation of human diversity as the explanation of problems in social scientific generalisations to be flawed in its own terms. The suggested solutions merely renamed the categories of the problem.

These issues suffuse the social sciences from the most general considerations of their nature to the most unreflecting empiricism of cultural differences in values and behaviour. We attempt to connect the specific and the general in our treatment of explanations, though we particularly emphasise general arguments where the issues are dealt with overtly and self-consciously. Of necessity, our treatment is highly critical, but, in choosing the ground for criticism, we have followed a course previously suggested by Talcott Parsons. He argued that the problems intrinsic to an explanatory undertaking were clearest in the best exponents of that undertaking. They, more than anyone else, would perceive, accept and seek to locate what he called the 'residual' categories of the theories which contradicted the central thrust. In order to demonstrate the generality of the issues we raise, we have chosen practitioners across theoretical and national traditions. We deal with non-Marxist and Marxist writers, with British, continental European and North American writers. In each case, those who receive detailed treatment have been chosen for the prominence and the rigour of their arguments. In lesser practitioners, as Parsons observed, the problems of the general position are either unrecognised or obscured. In those we deal with, the issues are explicit, even if the treatments are unsatisfactory. 
We can find, in every writer, a simultaneous dissatisfaction with claims for a deterministic, structural social science and with a practically unlocated cultural inquiry. Neither form, they believe, is adequate. Yet, what they offer in place of this 'contradictory dualism' is some combination of the two. By accepting the contradictory categories they build into the development of either, or both, the contradiction from which they start. Each of the components comes to take the form of its own negation. Thus, cultural categories come to have an external and constraining quality with unlocated changes in structure as the substance of social diversity. The interpretive requirement of a social science in which action is 'primitive' produces a series of contradictory 'positivisms' from which there is, apparently, no escape. Social science is restricted to the explication, or interpretation, of action and any problem of explanation is, therefore, a problem of social science, not of culture or society. However, the very process that in this way robs social science of a progressive thrust has similar consequences for action. Actors become bearers of culture and the differences between cultures have no evaluative consequences within the different cultures. Interpretive social science is proposed as a consequence of human creativity, but it annihilates the creativity it seeks to reflect.

That thrust in interpretive social science which argues that available theories are insufficiently sensitive and diverse to encompass the varieties of human experiences is positive, but only if it recognises the necessity of mutual coherence among the categories it accepts. In confronting contradictions and insisting that the only progressive treatment is their creative solution, we can free both action and social science from a restricting passivity.

We give illustrations of particular examples of explanatory deficiencies together with the coherence that new categories and processes can provide. In general, our aim is to turn social scientists towards their problems, cutting-off the routes provided by the flawed methodologies current in social theory by which they seek to escape. There is no escape. In most writers we deal with, the end of all their efforts is an explicit embrace of their problems as essentially insoluble and the substance of social life.

Some of the problems social scientists must address will be their problems, peculiar to their activities, but the most important are those for both citizens and social scientists. A creative social science dispels hopelessness as it solves problems and expands resources. 